\title{
Optimized Nano Grid Approach for Small Critical Loads
}

\author{
Daniel Todorov *, Venelin Todorov ${ }^{\dagger \ddagger}$, Sefka Fidanova ${ }^{\ddagger}$ \\ *University of Ruse Angel Kanchev, 8 Studentska Str, 7017 Ruse, Bulgaria \\ ${ }^{\dagger}$ Institute of Mathematics and Informatics \\ Bulgarian Academy of Sciences \\ 8 Acad. G. Bonchev Str., 1113 Sofia, Bulgaria \\ ${ }^{\ddagger}$ Institute of Information and Communication Technologies \\ Bulgarian Academy of Sciences \\ 25A Acad. G. Bonchev Str., 1113 Sofia, Bulgaria \\ Email: dltodorov@uni-ruse.bg,vtodorov@math.bas.bg, venelin@parallel.bas.bg, stefka@parallel.bas.bg
}

\begin{abstract}
This study is focused on the possibility of utilizing solar energy nano grids for feeding small scale critical loads. The reasons conditioning this necessity are reviewed and the strengths of small scale micro grids over the centralized type of powering are stated. On the basis of studies on renewable energy sources, photovoltaic converters are pointed to be most appropriate for small scale generation in urban conditions at specific geographical region. The loads of typical traffic lights show that they are relatively constant, which makes such consumers very suitable for micro or nano grids.
\end{abstract}

\section{INTRODUCTION}

$\mathbf{R}$ ENEWABLE energy sources (RES) have been widely discussed and applied last decades. Recently on focus have become full or semi autonomous smart systems providing electricity for number of applications. Depending on region specific nature resources, different RES my be utilized. It is important to study the best economic option, and also to study the load profiles in order to match production with demand. Because of erratic nature of some RES, it is necessary to design a storage system providing in periods of lacking RES generation or to relay on other energy at that time. Best option is to use multiple energy sources, however at a cost. For each application there is best option, but regarding complexity, price, space, convenience, etc., there is an optimal option.

\section{The need of Photovoltaics}

Last years there is great interest in solar energy. Solar cells may not be most efficient among renewable energy converters, but place a lot of convenient aspects, that led to their wide use. A study concerning the registers and issued licenses for RES energy trade of Sustainable Energy Development Agency (SEDA), Bulgaria [1], shows the distribution of renewable facilities in Bulgaria.

The work is supported by KP-06-M32/2-17.12.2019 'Advanced Stochastic and Deterministic Approaches for Large-Scale Problems of Computational Mathematics" and by the National Scientific Program "Information and Communication Technologies for a Single Digital Market in Science, Education and Security" (ICTinSES), contract No. D01-205/23.11.2018, financed by the Ministry of Education and Science. The work is supported by the Bulgarian National Science Fund under Project DN 12/5-2017 "Efficient Stochastic Methods and Algorithms for Large-Scale Problems".
In this section we will discuss the reasons for using photovoltaics. The results show that one of the main utilizable RES is solar power - Fig 1. On Fig. 2 this distributions are displayed graphically in percents for Bulgaria and Central North region. For central north region, solar energy is most used, because there are not much winds or possibilities of hydro generation. In urban conditions there are lots of limitations for building large RES structures, however the existing roof constructions or poles are appropriate for installation of photovoltaic (PV) modules. Furthermore for small scale generation PVs are one of the most suitable RES. However, in cases where an abundance of another energy source is present - like winds, small scale wind turbines may be more appropriate than solar cells. With the development of energy harvesting technologies, new energy sources may emerge and as soon as they become cost comparative to solar cells the current situation may change. We believe, that the road itself and the weight of the vehicles may be used for better generation, when piezo, vibration or pneumatic harvesters are used, however the price of such implementation is prohibitive in the current situation. The yearly global irradiation for optimally inclined PV cells in central north region is estimated to be in the range $(1350 \ldots 1500) \mathrm{kWh} / \mathrm{m} 2$. For the other regions in Bulgaria and for some European countries it is respectively (1200...1500) kWh/m2 and (800...2200) kWh/m2. From [2] it can be noted, that significant amounts of solar irradiation are available during months April - September. During this period, solar cells are expected to be most efficient.

\section{THE NEED OF MICROGRIDS}

The existing electrical grid has mainly centralized structure, providing decent quality of power and reliability, but because of its complexity and largely spread transmission lines, there exist possible failure points. Some publications blame mainly the grid itself instead of the central power plants [3], [4]. The modern consumers have lots of digital equipment that require high level of reliability and quality of the supplied energy. Economy and industry also relay on digital equipment. For certain types of consumers, outages can impose unwanted risks, 


\begin{tabular}{|c|c|c|c|c|c|c|c|c|c|c|c|c|c|c|}
\hline \multirow[b]{2}{*}{ 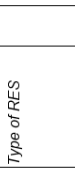 } & \multicolumn{2}{|c|}{\begin{tabular}{|l}
$\begin{array}{l}\text { Totall for } \\
\text { Bulgaria }\end{array}$ \\
\end{tabular}} & \multicolumn{2}{|c|}{ North-west } & \multicolumn{2}{|c|}{$\begin{array}{l}\text { Cental- } \\
\text { North }\end{array}$} & \multicolumn{2}{|c|}{ North-east } & \multicolumn{2}{|c|}{ South-west } & \multicolumn{2}{|c|}{$\begin{array}{l}\text { Central- } \\
\text { south }\end{array}$} & \multicolumn{2}{|c|}{ South-east } \\
\hline & 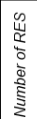 & 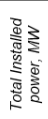 & 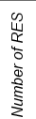 &  & 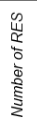 & 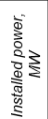 & 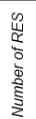 &  & 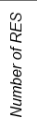 & 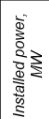 & 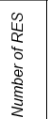 &  & 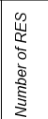 & 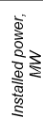 \\
\hline $\begin{array}{l}\begin{array}{l}\text { Wind } \\
\text { energy }\end{array} \\
\end{array}$ & $\stackrel{?}{=}$ & 总 & $\infty$ & $\stackrel{\sim}{\stackrel{N}{I}}$ & - & 吕 & $\stackrel{\infty}{\stackrel{\circ}{\circ}}$ & 常 & N & 㖞 & & & is & 吕 \\
\hline $\begin{array}{l}\text { Hydro } \\
\text { Energy }\end{array}$ & ส & 总 & is & $\begin{array}{l}F \\
\dot{q} \\
8\end{array}$ & $\stackrel{\circ}{\circ}$ &  & $m$ & 兽 & 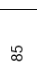 & 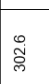 & 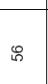 & 离 & $=$ & $\begin{array}{l}8 \\
0 \\
0 \\
0\end{array}$ \\
\hline $\begin{array}{l}\text { Solar } \\
\text { Energy }\end{array}$ & ב్ & 喝 & $\stackrel{ \pm}{\stackrel{ \pm}{*}}$ & 尊 & $\approx$ & 感 & g & 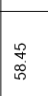 & $\stackrel{0}{=}$ & 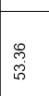 & 이 &  & 商 & 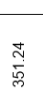 \\
\hline $\begin{array}{l}\text { Lanofitill } \\
\text { Gas }\end{array}$ & - & $\stackrel{\mathscr{O}}{\infty}$ & & & & & & & - & $\begin{array}{l}\infty \\
0 \\
0\end{array}$ & & & & \\
\hline Biomass & a & $\begin{array}{l}\stackrel{\infty}{\varrho} \\
\stackrel{0}{0}\end{array}$ & & & & & & & - & n & N & $\simeq$ & - & ल. \\
\hline $\begin{array}{l}\text { Waste } \\
\text { water }\end{array}$ & $N$ & 官 & & & - & న్ & & & - & $\frac{9}{m}$ & & & & \\
\hline 殒 & $\underset{\mathscr{q}}{\not{q}}$ & 第 & $\dddot{\mathscr{8}}$ & $\begin{array}{l}\mathscr{8} \\
\dot{0} \\
\stackrel{\sigma}{\sigma}\end{array}$ & $\stackrel{\infty}{\infty}$ & 总 & $\dddot{\varnothing}$ & 兽 & 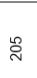 &  & 怘 & $\frac{0}{N}$ & $\ddot{q}$ & 占 \\
\hline
\end{tabular}

Fig. 1. Distribution of RES facilities in Bulgaria and in each of its 6 regions (According to SEDA)

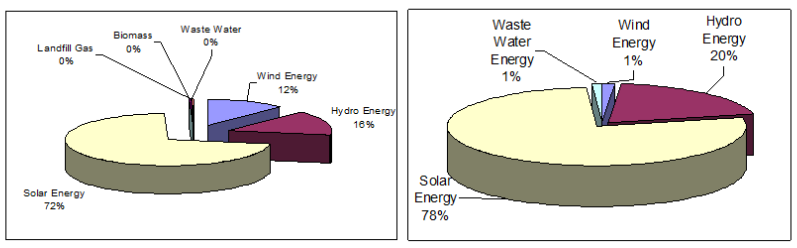

Fig. 2. The distribution of RES energy facilities by types in Bulgaria and central north region

or can threaten safety. Such consumers are facilities part of national defense and security, water treatment, communication, hospitals, traffic signals, data storage facilities, etc. Providing high reliability to such consumers would be too expensive if only the main grid was used with its current structure [5]. If possible, additional bypass wiring is done together with auto transfer switches, or diesel backup generators or large scale UPS systems. One of the main types of failure in the electrical grids are outages. They are affecting negatively various processes. For e.g. in 2012, for Bulgaria the number of reported grid outages is 1375 with total duration of $5005 \mathrm{~h}$. The Electricity System Operator, has reported only the outages of $110 \mathrm{kV}$ substations - which is small number for each city, but there also exist more outages that occur locally, due to accidents or power line interruption, that are not reported. Outages are also present due to local or hierarchically bigger node failures or scheduled maintenance of electricity grids. Practically there is no available information about the real number of outages for end consumer in the reports. Most of outages are with short duration, but they can still interrupt or stop various processes in the consumer side. So there must be used another solution for the consumers that require high reliability and quality of power. Microgrids may be capable of fulfilling this demand, because of their ability to use multiple locally distributed power sources (generators and energy storage devices) and to isolate from the grid whenever there is a problem in it. Further more modern controllers make it possible to automatically control loads by priority, leaving only crucial loads online. A smaller structure, recently defined as nanogrid [6], [7], resembles the microgrid approach, however it is much smaller in terms of capacity and structure complexity. Nanogrids are also capable of maintaining good power quality during sags, surges and outages in the outside grid. On Fig. 3 it is presented a block schematic of a small scale microgrid. The controller makes decision for switching between sources of energy - utility grid(s), local generators and storage. Depending on the control algorithm critical load will always stay powered. If no utility power is present and not enough RES generation is available it may switch to alternative grid if available (like auto transfer switches) or internal energy storage devices. In the worst case when storage begins depletion, controller may disconnect non critical loads. Furthermore additional communication is provided with maintenance services, server or another microgrid's controller.

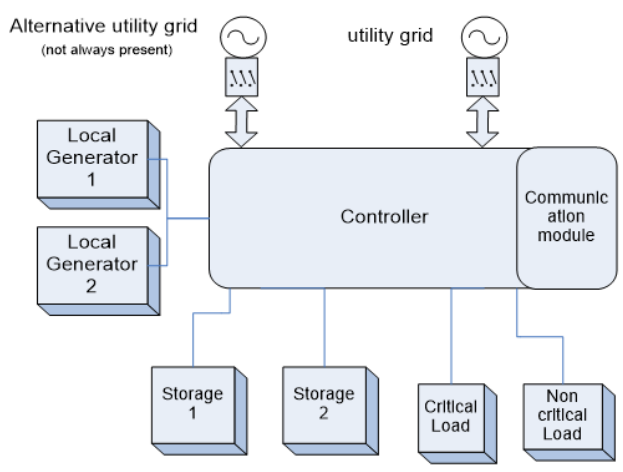

Fig. 3. Small scale microgrid. The controller is responsible for switching between power sources - utility grid, local generators and storage and communication within and outside the grid

The microgrid controller also compensates the erratic nature of RES, making the whole system operate constantly and reliably. PV systems part of small local micro grid are becoming increasingly attractive, because of their advantages concerning sustainability, efficiency and price. PV systems are very suitable for supplying small loads in cities and remote areas, because solar irradiation is nearly ubiquitous, unlike wind or hydro energy. The efficiency of solar energy converters is subject to constant improvements and the prices going down, because of demand and high manufacturing rates. However a microgrid may operate with any other RES or battery energy storage devices if there is abundance of some other local source of energy. It can also make use of several sources at the same time. 


\section{DETERMINE THE LOADS}

In this paper, the possibility of using microgrids for supplying power to publicly significant consumers - traffic lights (TL) is considered. An research of the typical loads of TL is required for this purpose. A study concerning the electrical consumption of sample of TL is made. For comparison purpose there is included old consumption data obtained in the past from non modernized TLs using non energy efficient loads, because unfortunately they are still present in some parts of the world due to lack of funds. Some TLs are studied theoretically, by using data about operation cycle and loads switched during each phase (Fig. 4). As seen the load of typical LED-only TL is very small $(0,28 \mathrm{~kW})$, while the load of inefficient TL with inefficient lighting modules is several times higher $(1,2 \mathrm{~kW})$. In the theoretical load models, the transients during loading capacitors of LED power supplies are not taken into account, because they are different for the various LED modules, depending mainly on wattage rating of the power supply module and are relatively short. Furthermore most of the SMPS found in these LED modules have inrush current limiter and power factor correction. In some LED heads, the manufacturers has included active loads to obtain compatibility with controllers monitoring current, also to minimize cable and terminals voltage leaks and transfers between signals, but this increases consumption while dissipates heat and worsens efficiency for the sake of safety. Statistical data for the real electrical energy consumption is obtained from archives of periodic meter readings. The statistical characteristics of the loads of two LED and two old data from inefficient TLs mean value, standard deviation, coefficient of variation and confidence interval at confidence probability 0.95 are shown in Table I. We use the following notations: Mean Value (MV), Standard Deviation (SV), Coefficient of Variation (CV), Confidence + limit $(\mathrm{C}+\mathrm{l})$, Confidence - limit $(\mathrm{C}-\mathrm{l})$

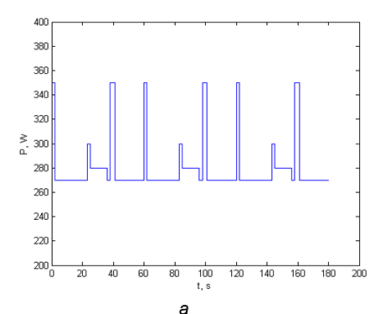

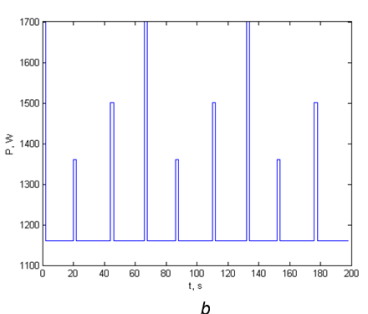

Fig. 4. Theoretical load profile of: a) LED TL; b) old inefficient TL

The small deviations are caused mainly by inaccuracy in data collection and others factors like luminaire type or group of luminaires replacement during maintenance. This means, that probabilistic and unpredictable nature of the load is not observed, which is very convenient in designing micro grids, that fulfills the demand of each consumer. As seen for the case with old TLs, it was practically impossible to implement such PV system, while on LED efficient TLs it is easily achievable. Most of the TL are operating in normal mode in the time
TABLE I

CALCULATED VALUES FOR DAILY MEAN VALUE OF CONSUMED ENERGY AND ITS STATISTICAL CHARACTERISTICS - STANDARD DEVIATION, COEFFICIENT OF VARIATION, AND CONFIDENCE INTERVALS AT 0.95 CONFIDENCE PROBABILITY

\begin{tabular}{|c|c|c|c|c|c|}
\hline Object & MV, kWh & SD , kWh & CV & C+l, kWh & C-1, kWh \\
\hline TL LED1 & 4,62 & 1,12 & 0,24 & 5,34 & 3,91 \\
TL LED2 & 6,83 & 0,39 & 0,06 & 7,08 & 6,58 \\
TL old1 & 24,43 & 2,16 & 0,09 & 25,81 & 23,06 \\
TL old2 & 39,67 & 2,84 & 0,07 & 41,47 & 37,87 \\
\hline
\end{tabular}

period $(6: 00 \ldots 22: 30 \mathrm{~h})$, during rest of the time, they are in flashing mode, with lowered consumption, however there are also cases where they operate constantly as well, this means that the electrical energy produced from the PV modules would feed, for considerable part of time, the TLs that operate only daily, which will Lead to significantly minimized grid consumption, and extended accumulating media lifecycles.

\section{NUMERICAL EXAMPLE}

Having determined the Load Profiles and with the case of deterministic nature of loads is an easy way to implement a microgrid. For preliminary generated values of solar irradiation we use database from [8] for a point in North Bulgaria with tilt angle $-30 \mathrm{deg}$. In our example we use $1 \mathrm{~kW}$ PV installation, with battery backup, but instead of using battery energy to increase income we would prefer to reserve it for safety in case of emergency outage. Thats why we do not include charge/discharge cycles in our graphs on Fig. 5 and Fig. 6. We will take two cases for solar irradiation at summer maximum about whole June, and minimum at 20 December.

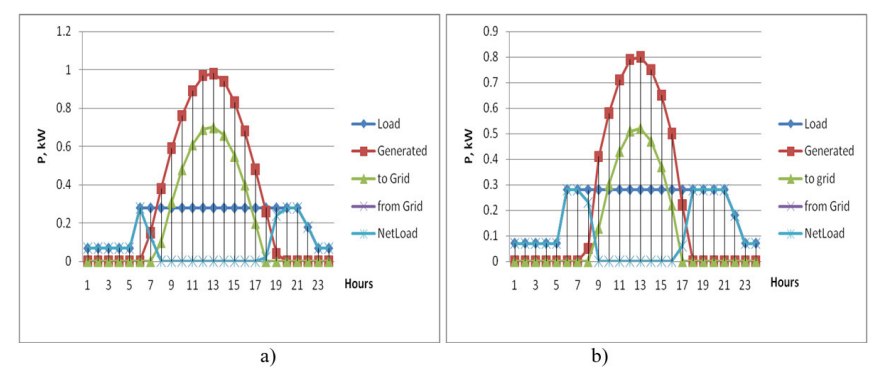

Fig. 5. Hourly diagram Load Profiles of traffic light, Generated solar energy, Energy from and to utility grid: a) June; b) December.

As seen in summer time the expected solar generation starts after 6 till 20 o'clock, and in winter time it is smaller period from 7 till 17 o'clock. Also the maximum generation energy is reduced $20 \%$. Without using the storage the daily income is from 0.31 to $2.8 \mathrm{~kW}$, respectively for winter and summer. If bigger PV generators are used this will increase income but price, and space required also increase.

The flowchart of proposed optimized control algorithm for the specific Nanogrid is given on Fig. 7, where Ppv is the generated power from photovoltaics, $\mathrm{Pl}$ - measured power of 


\begin{tabular}{|c|c|c|c|c|c|c|c|}
\hline & & Summer June & & & Winter Dec 2 & & \\
\hline & & & & from & & to & from \\
\hline $\mathrm{H}, \mathrm{h}$ & $\begin{array}{l}\text { Load, } \\
\text { kW }\end{array}$ & $\begin{array}{l}\text { Generated, } \\
\text { kW }\end{array}$ & $\begin{array}{l}\text { to Grid, } \\
\mathrm{kW}\end{array}$ & $\begin{array}{l}\text { Grid, } \\
\text { kW }\end{array}$ & $\begin{array}{l}\text { Generated, } \\
\text { kW }\end{array}$ & $\begin{array}{l}\text { grid, } \\
\mathrm{kW}\end{array}$ & $\begin{array}{l}\text { Grid, } \\
\text { kW }\end{array}$ \\
\hline 1 & 0.07 & 0 & 0 & 0.07 & 0 & 0 & 0.07 \\
\hline 2 & 0.07 & 0 & 0 & 0.07 & 0 & 0 & 0.07 \\
\hline 3 & 0.07 & 0 & 0 & 0.07 & 0 & 0 & 0.07 \\
\hline 4 & 0.07 & 0 & 0 & 0.07 & 0 & 0 & 0.07 \\
\hline 5 & 0.07 & 0 & 0 & 0.07 & 0 & 0 & 0.07 \\
\hline 6 & 0.28 & 0 & 0 & 0.28 & 0 & 0 & 0.28 \\
\hline 7 & 0.28 & 0.15 & 0 & 0.13 & 0 & 0 & 0.28 \\
\hline 8 & 0.28 & 0.38 & 0.1 & 0 & 0.05 & 0 & 0.23 \\
\hline 9 & 0.28 & 0.59 & 0.31 & 0 & 0.41 & 0.13 & 0 \\
\hline 10 & 0.28 & 0.76 & 0.48 & 0 & 0.58 & 0.3 & 0 \\
\hline 11 & 0.28 & 0.89 & 0.61 & 0 & 0.71 & 0.43 & 0 \\
\hline 12 & 0.28 & 0.97 & 0.69 & 0 & 0.79 & 0.51 & 0 \\
\hline 13 & 0.28 & 0.98 & 0.7 & 0 & 0.8 & 0.52 & 0 \\
\hline 14 & 0.28 & 0.94 & 0.66 & 0 & 0.75 & 0.47 & 0 \\
\hline 15 & 0.28 & 0.83 & 0.55 & 0 & 0.65 & 0.37 & 0 \\
\hline 16 & 0.28 & 0.68 & 0.4 & 0 & 0.5 & 0.22 & 0 \\
\hline 17 & 0.28 & 0.48 & 0.2 & 0 & 0.22 & 0 & 0.06 \\
\hline 18 & 0.28 & 0.26 & 0 & 0.02 & 0 & 0 & 0.28 \\
\hline 19 & 0.28 & 0.04 & 0 & 0.24 & 0 & 0 & 0.28 \\
\hline 20 & 0.28 & 0 & 0 & 0.28 & 0 & 0 & 0.28 \\
\hline 21 & 0.28 & 0 & 0 & 0.28 & 0 & 0 & 0.28 \\
\hline 22 & 0.18 & 0 & 0 & 0.18 & 0 & 0 & 0.18 \\
\hline 23 & 0.07 & 0 & 0 & 0.07 & 0 & 0 & 0.07 \\
\hline 24 & 0.07 & 0 & 0 & 0.07 & 0 & 0 & 0.07 \\
\hline ta & 5.15 & 7.94 & 4.7 & 1.9 & 5.46 & 1.99 & 1.68 \\
\hline
\end{tabular}

Fig. 6. Hourly diagram Load Profiles of traffic light, Generated solar energy, Energy from and to utility grid: a)June; b)December.

the load, Pgrid - power from to grid, Pbatt - power from to storage media. Fig 7 presents the optimized control algorithm under consideration.

\section{CONCLUSION}

Knowing Load Profiles, together with the information about solar irradiation in the area of application, can be used for optimal design and implementation of PV nano grids. That can help increase reliability and efficiency locally. Such micro grids are necessary even only as protection, not counting the efficiency aspect, because there are cases when power quality worsens for short times within or outside the standard requirements. Modern telecommunications and embedded devices make it possible to easily implement not only power protection for short times like traditional UPS, but such controllers can also reconfigure the whole local grid so that it can maintain stability for prolonged time. Controllers can always send signals to the maintenance service when they have limited amount of reserved resources left, or can send signals to the connected devices to securely switch to emergency mode, stop or hibernate if possible. Unexpected power outage is extremely dangerous for digital equipment, many industrial processes and

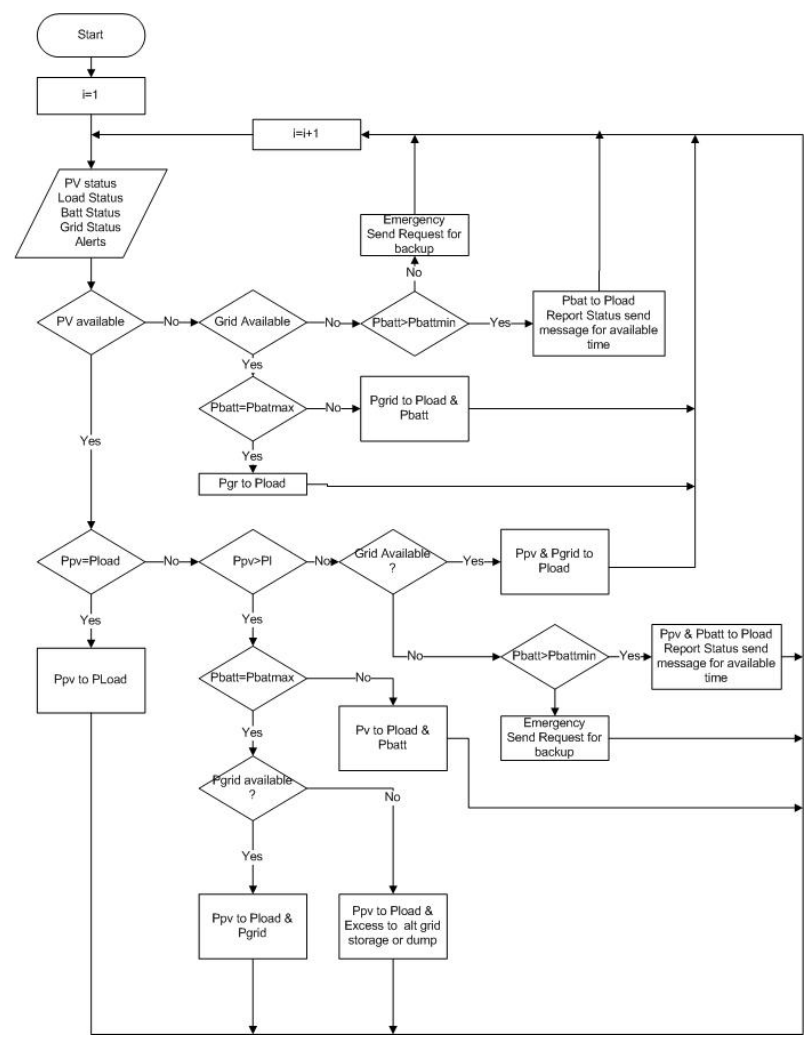

Fig. 7. The flowchart of proposed control algorithm for the specific Nanogrid

traffic safety. Putting all crucial loads inside protected and self-available (for specific time) network, ensures long term efficient operation during unfavorable conditions.

\section{REFERENCES}

[1] Sustainable Energy Development Agency, http://www.seea.government. bg/;

[2] Mihailov N 2014 Renewable Energy Sources and Intelligent Electrical Grids, Presentation, University of Ruse and Regional Academic Council of BAS, Ruse;

[3] McLinn J 2009 Major Power Outages in the US and around the World, Annual technology report of the IEEE Reliability Society http://paris.utdallas.edu/IEEE-RS-ATR;

[4] Electricity System Operator Annual report http://tso.bg/Reports;

[5] Fereidoon P 2011 Smart Grid Integrating Renewable, Distributed \& Efficient Energy, Academic Press, 2011;

[6] Nordman B, Christensen K 2013 Local Power Distribution with Nanogrids, International Green Computing Conference, Arlington, VA;

[7] Schonberger J, Round S, Duke R 2005 Decentralized source scheduling in a model nanogrid using DC bus signaling, , AJEEE.

[8] http://www.debarel.com/ 